\title{
Psychiatric Disorders with Hearing and Speech Impairment in Nepalese Children
}

\author{
Krishna Prasad Pathak ${ }^{1 *}$ and Tara Gaire ${ }^{2}$ \\ ${ }^{1}$ Assistant Professor, Nepal Open University, Nepal \\ ${ }^{2} \mathrm{MScN}$, Innovative Health Science College, Kathmandu \\ *Corresponding Author: Krishna Prasad Pathak, Assistant Professor, Nepal Open University, Nepal.
}

Received: June 18, 2019; Published: July 04, 2019

DOI: 10.31080/ASMS.2019.03.0344

Psychiatric is a vast and unique area for research. This is a branch of psychology. The term psychiatric disorders means the study and treatment of mental illness (Oxford Dictionary). Some times it is known as a mental health disorders or mental health illnesses. Many causes lead to be psychiatric disorder. The diagnostic statistical manual (DSM) of mental disorder argue that anxiety, social mal adjustment, dementia, personality disorders, cognitive disorder, communication disorder, language learning disorder will appears as a psychiatric disorder in children. Till now the exact cause of psychiatric disorders is not well known. Mental health experts believe that psychiatric disorders result from a combination of genetic or inherited dispositions and a triggering event. It may include physical health problems, regular unsuccessful result, stresses of various types in developing stages, environmental factors, and even physical health problems like; hearing and speech problem . Richard Hackett [1] finds that the majority of population of children in developing countries adversely affected by this psychiatric disorder. With them there is close relation in Genetic and parental influences. So, their behaviors and adjustment of children can be affected by a wide range of educational achievements and social adjustment. Many scholars argue that the prevalence rate of psychiatric disorder in developing countries school's have more than $8.3 \%$ in Beijing, china, 44\% In India and 29\% in Sudan (yugeng., et al. 1989), (sekar., et al. 1983) and (Giel., et al. 1981) [1].

Psychiatric aspects of speech impairment

The sound comes out of mouth is called speech. It is the process of communication with each others. When it is no understood by others there is a problem. In human life communicable and communication ability is very important to the quality of life [2]. Identification and intervention for significant hearing loss and speech is necessary for academic success and social emotional de- velopment in children. Both speech and hearing Impairment helps to lead the prevalence of psychiatric disorder. This is at risk with children (James M. Baum, 2007). Cant well and backer [3], find that due to the speech problem in children they have an increased prevalence of psychiatric disorder. Likewise, the problem of speech clinicians being faced with sizable numbers of severely and emotionally distributed children had been extensive speech therapy and educational remediation and they explore that the children have some abnormal behavior like, Nail biting, truancy from school and problem at home. Normally, the problems feel in two groups; 1) The inhibition and the shyness, 2) Hyperactive, aggressive and destructive behaviors' [4] and many others abnormal behavior was found than normal children, including inappropriate facial expression, gestures problems in coordination, abnormal attention span etc. (Affolter., et al. 1974). The above noted result was tested with 30 language deficient children between the age of 3-10 years. Similarly, psychiatric disorders remains more prevalent in the speech and language disordered children than normal speech- disordered children [3].

Psychiatric aspects of hearing impairment

Generally, hearing impairment means such a condition that is impossible to generalize about the psychiatric consequences of hearing impairments as a multifaceted condition with medical and cultural aspects and social aspects. Children with hearing impairment follow many different developmental pathways, something's up to join the deaf society (peter hindely, st. George, hospital medical school London u U.K. Psychiatric aspects of hearing).

Hearing impairment has attracted less public concern in developing countries than visual impairment (willson .1985, white. 1988). Ignoring the educational or social disability of hearing impairment and easily treatable or preventable causes. All over the 
world, deafness having commonest single disability in developing countries. It is being an invisible disability in rural areas of developing places. Without appropriate hearing function no one is able to develop normal speech, which are frequently unable to benefit from education and social prospects. (Bpinos: Britain Nepal Otology services, survey report, 1991).

Many studies show that hearing impairment is unique with each child like; pre lingual/post lingual, unilateral or bilateral hearing impairment and furthermore, there is level of hearing impairment, for example, Mild-20 DBHL, Child-20-40, Moderate 40-60, Severe 70-90, Profound-91 or greater as well as, there becomes the problem with ear (right, left and both). Peter Hindley shows that there is no certain term of hearing impairment. It covers such a broad range of conditions that become impossible to generalize about the psychiatric consequences of hearing impairment as a unitary situation but hearing impairment can be generalized by medical persons and audiologist, and there remains many causes: genetic causes, communicable disease, disability, environment, injury medication brain disease etc. to lead the hearing impairment (Hearing Science Direct Journal, 2000).

Children develop hearing, speech, language, and skills at different ages. However, hearing loss can lead to be delay in their abilities to make proper learn to speak, sounds, and communicate with each others. Many studies show that hearing impaired children have many problems in their developmental aspects, social aspects; educational aspects. The reality is that mothers are the first school in their developmental periods. In this case mother's role play seems a vital and second role in school by the school teachers for their further life. Hearing impairment was predominantly described as having behavior disorder and then a relative lack of psychiatric disorder. Neither they can express their feelings nor improve their ability to speak with other. So, it is needed to study in this field. Although, there are very few studies on psychiatric assessment of deaf children (Jankins and chess, 1991, kennedy, 1942). According to Hindley findings the psychiatric disorder was very high in school. But there were differences between the hearing impaired unit and deaf school groups on the self-image and schools.

What is the problem?

Unless the appropriate findings will not identified, children's developments aspects, social aspects, mental aspects educational achievements wouldn't be sound. So, for children should be specific policy in school and at home to immerge their potentialities in their life. Many problems are hidden with that speech and hearing impairments. Most of the developing countries could not address their need in school. Just they will complete their duty successfully but they do not know the main impact factor in low result of education.

Nepal is a landlocked and developing country in a south Asia having such problem in Nepali children. In Nepal, there is a concept of kindergarten in private sector. Kindergarten Education in Nepal is near about similar with Indian and Hong Kong education system. The kindergarten education system in Nepal runs as a private sector and medium of teaching is English except one for Nepali Language. The kindergarten age starts from age of two until they are at least 5 years old. The framework of kindergarten in Nepal have following grades: Nursery/play Group-2-3yrs old children, Lower kindergarten/LKG-3-4 yrs old children, Upper kindergarten UKG 4-5 years old children. Psychologists argue that according to their developmental phase this age group (kindergarten group) is very important to learn in human developmental age. But the problem is completely ignoring in Nepal. In Nepal generally children are beyond the concern of parents and schoolteacher. Due to less concern of the parents and schoolteacher they are not able to improve their disabilities .In this way Nepali children are facing psychiatric problems such as phobias, change in appetites, loss of interest in activities, recurring thoughts of death or suicide, loss of energy, helpless, fatigue. Low self-stem, depression anxiety, conduct disorder, deficit disorder etc. Mainly in developing countries hearing and speech problem is less concern than visual impairment (willson, 1985, White, 1988). Many scholars show that the suffered numbers of children is greater in developing countries than in developed countries.

By this, the conclusion can be drawn that Nepali children are also the part of that numbers. But till date, no research can be found that were conducted on the issues psychiatric disorders with hearing and speech impairments in Nepali children.

So, now a day it is having to compulsory to check the hearing and speech impairments and any developmental disorders in the first entry time of school, when a pupil becomes enroll. It helps to the parents and school teachers to find out the difficulties in learning earlier (Ohio Department of Health, hearing screening requirements and guidelines for school-aged children, 2007). So, today's children are future's pillar of nation. Therefore to address the issues of Psychiatric Disorders in Children with Hearing and Speech 
Impairment in Nepal a large scale of study is needed to find out the psychiatric disorders and proper solution with hearing and speech impairments of Nepali children [5-16].

\section{Bibliography}

1. Richard Hackett. "The prevalence and Association of psychiatric disorders in children in kerala, South India, Rajal Oldham, Hospital, U.K". Journal of Child 40.5 (1999): 801-807.

2. Barr RD., et al. "Health related quality of life in survivors of life in supervisors of wilms tumor and advanced nureoblastoma: a cross sectional study". Journal of clinical oncology 18.18 (2000): 3280-3287.

3. Cantwell DP and Baker L. "Academic failure in children with communication disorder". 19 (1980): 579-591.

4. Caceres VA. "Retardo del. Lengauge verbal". Revista de neuropsi quiatria 34 (1971): 210-226.

5. Griffiths CPS. "A follow of study of children with disorder of speech". British Journal of Diseases of the Chest 4 (1969): 4656.

6. Hindley PA. "Signs of feeling: A prevalence study of psychiatric disorder in deaf and partially Hearing children and adolescents. London: Royal National Institute for the Deaf Research Report (1993).

7. Jamie M Baum. "Development of high frequency hearing loss questionnaire for children". Independent studies and coop stones paper 171. Published Thesis program in Audiology and communication Science, Washington university school of Medicine (2007).

8. Jenkins IR and Chess S. "Psychaitric evaluation of perceptually impaired children: hearing and visual impairment”. (1991).

9. Lorian Backer and dennis p Cantwell. "Psychaitric disorder in children with different types of communication disorders". Journal of Communication Disorders University of California at Loss Angeles (1982).

10. Malandraki G and Okalidou A. The application of PECS in children with autism and deafness: A case study". Focus on Autism and Other Developmental Disabilities 22 (207): 23-32.

11. McGee., et al. "Behaviour problems and otitis media with effusion: A Report from the Dunedin, Multidisciplinary child Development Study" New Zealand Medical journals 95 (1982): 655-657.
12. Okalidou A and Kampanaros M. "Teacher perceptions of communicative impairment at screening stage in pre-school children living in Patras, Greece". International Journal of Communication Disorders 36.2 (2001): 489-502.

13. Papadopoulos K., et al. "Perception of synthetic and natural speech by adults with visual impairments". Journal of Visual Impairment and Blindness 103.7 (2009): 403-414.

14. Peter Hindley. "Psychiatric Aspects of Hearing Impairments". Journal of Child Psychology Psychiatric 38.1 (1997): 101-107.

15. Petinou K and Okalidou A. "Speech patterns in Cypriot-Greek late talkers". Applied Psycholinguistics 27 (2006): 335-353.

16. Weiner P S. "The emotionally disturbed child in the speech clinic: some consideration". The Journal of speech and hearing disorders 33 (1968): 158-167.

\section{Volume 3 Issue 8 August 2019 (C) All rights are reserved by Krishna Prasad Pathak and Tara Gaire.}

